\title{
Nanoparticles of Conjugated Methotrexate-Human Serum Albumin: Preparation and Cytotoxicity Evaluations
}

\author{
Azade Taheri, ${ }^{1}$ Fatemeh Atyabi, ${ }^{1,2}$ Faranak Salman Nouri, ${ }^{1}$ Fatemeh Ahadi, ${ }^{1}$ \\ Mohammad Ali Derakhshan, ${ }^{1}$ Mohsen Amini, ${ }^{3}$ Mohammad Hossein Ghahremani, ${ }^{2,4}$ \\ Seyed Nasser Ostad, ${ }^{2,4}$ Pooria Mansoori, ${ }^{5}$ and Rassoul Dinarvand ${ }^{1,2}$
}

\author{
${ }^{1}$ Department of Pharmaceutics, Faculty of Pharmacy, Tehran University of Medical Sciences, P.O. Box 14155-6451, Tehran, Iran \\ ${ }^{2}$ Nanotechnology Research Centre, Faculty of Pharmacy, Tehran University of Medical Sciences, Tehran, Iran \\ ${ }^{3}$ Department of Pharmacology, Faculty of Pharmacy, Tehran University of Medical Sciences, Tehran, Iran \\ ${ }^{4}$ Drug Design and Development Research Centre, Faculty of Pharmacy, Tehran University of Medical Sciences, Tehran, Iran \\ ${ }^{5}$ Faculty of Medicine, Ahvaz Jundishapur University of Medical Science, P.O. Box 12244-9876, Ahvaz, Iran
}

Correspondence should be addressed to Rassoul Dinarvand, dinarvand@tums.ac.ir

Received 1 June 2010; Revised 5 July 2010; Accepted 1 August 2010

Academic Editor: Libo Wu

Copyright () 2011 Azade Taheri et al. This is an open access article distributed under the Creative Commons Attribution License, which permits unrestricted use, distribution, and reproduction in any medium, provided the original work is properly cited.

Methotrexate-human serum albumin conjugates were developed by a simple carbodiimide reaction. Methotrexate-human serum albumin conjugates were then crosslinked with 1-ethyl-3-(3-dimethylaminopropyl) carbodiimide HCl (EDC) to form nanoparticles. The size of nanoparticles determined by laser light scattering and TEM was between 90-150 nm. Nanoparticles were very stable at physiologic conditions (PBS pH 7.4, $37^{\circ} \mathrm{C}$ ) and after incubation with serum. The effect of amount of EDC used for crosslinking on the particle size and free amino groups of nanoparticles was examined. The amount of crosslinker showed no significant effect on the size of nanoparticles but free amino groups of nanoparticles were decreased by increasing the crosslinker. The physicochemical interactions between methotrexate and human serum albumin were investigated by differential scanning calorimetry (DSC). Nanoparticles were more cytotoxic on T47D cells compared to free methotrexate. Moreover, methotrexate-human serum albumin nanoparticles decreased the IC50 value of methotrexate on T47D cells in comparison with free methotrexate.

\section{Introduction}

HSA as a drug carrier represents a new strategy for controlled drug delivery. Its use as a polymeric particulate system $[1,2]$ or conjugates with drug molecules [3] has been reported. HSA conjugates can localize drugs in special site and control the release of drugs. Therefore, HSA is considered as good candidate for drug delivery in cancer therapy [4]. MTX is a folate antagonist and is used widely in the treatment of human cancer. MTX induces cancer cure in women suffering from metastatic choriocarcinoma $[5,6]$. Moreover this antimetabolite has several defects. After I.V. administration, MTX is rapidly cleared from circulation through the kidneys. Mean distribution half-life of MTX is 1.5-3.5 hrs [7]. Consequently, tumor exposure time of MTX is short. Several efforts have been made to reduce MTX defects. In a study, MTX has been physically incorporated into bovine serum albumin nanoparticles to target and control the release of MTX in tumor environment [8]. A disadvantage of this system may be the increased chance of tumor resistance due to the sustained release of methotrexate. Moreover, nun-targeted release of drugs may induce side effects [9]. Conjugation of cytotoxic drugs to carriers decreases the systemic toxicity and increases their therapeutic benefits [10]. HSA plays an important role as a nutrient for proliferating tumors; consequently HSA is a very good candidate for conjugating cytotoxic drugs [11]. Preparation of MTX-HSA conjugates have been reported before. Endo et al. studied the cytotoxicity of conjugated MTX on MM46 cells [12]. They showed that free MTX was more cytotoxic than MTX-HSA conjugates on the tumor cell line. In this study we have prepared MTX-HSA nanoparticles 
using MTX-HSA conjugates. MTX-HSA nanoparticles with a size of less than $150 \mathrm{~nm}$ have a good chance to reach tumor cells through the porous membranes of vascular system as a result of enhanced penetration and retention (EPR) effect. Previous studies have shown the benefit of nanoparticles for the delivery of cytotoxic agents [13]. Moreover, the release of free MTX from nanoparticles in serum would be low thus fewer side effects would be expected [10]. The physicochemical characterizations of nanoparticles, the effect of the amount of crosslinker on particle size and free amino groups of nanoparticles, and stability properties of the MTX-HSA nanoparticles were evaluated.

\section{Materials and Methods}

2.1. Materials. Methotrexate USP was kindly donated by Cipla Pharmaceutical Co., India. 1-ethyl-3-(3dimethylaminopropyl) carbodiimide $\mathrm{HCl}$ and human serum albumin (HSA) were purchased from Sigma (Steinheim, Germany). Total protein kit (Micro Lowry) was from Sigma (Saint Louis, USA). PMRI-1640 modified medium and penicillin/streptomycin solution were obtained from Gibco Invitrogen (Carlsbad, CA). MTT was obtained from Sigma (St. Louis, USA). Methanol and acetonitrile used as mobile phase in HPLC and DMSO were purchased from Merck (Darmstadt, Germany). Deionized water was used throughout the experiment. All other chemicals used were of reagent grade.

2.2. Preparation of MTX-HSA Conjugates. MTX (20 mg) with EDC $(15 \mathrm{mg})$ was dissolved in DMSO $(1.25 \mathrm{ml})$. The solution was placed in water bath at $50^{\circ} \mathrm{C}$ for $15 \mathrm{~min}$. Then the solution was cooled to room temperature and was added to HSA solution (250 mg HSA in $2 \mathrm{ml}$ PBS pH 7.4). After reaction time, unreacted MTX, EDC, and DMSO were removed using Amicon Ultra-4 Centrifugal Filter Devices (Millipore, USA).

2.3. Gel Permeation Chromatography (GPC). Gel permeation chromatography was carried out using a GPC system (Agilent 1100 Liquid Chromatographer, Agilent technologies, USA) with a refractive index detector (Agilent technologies, USA) and PL Aquagel-OH mixed gel-filtration column $(300 \times 7.5 \mathrm{~mm}$ internal diameter, pore size $8 \mu \mathrm{m}$; Agilent technologies, USA). Water at a flow rate of $1.2 \mathrm{ml} / \mathrm{min}$ was used as mobile phase. All experiments were performed at $23^{\circ} \mathrm{C}$. HSA $(50 \mathrm{mg} / \mathrm{ml})$ and MTX-HSA conjugates $(20 \mathrm{mg} / \mathrm{ml})$ were dissolved in water separately and were injected to GPC system. Figure 1 shows the GPC chromatogram of MTXHSA conjugate and HSA. The GPC chromatogram of MTXHSA conjugate showed a peak at $19.8 \mathrm{~min}$ whereas a single peak was found for HSA. No additional peak was detected for free MTX and HSA in the GPC chromatogram of MTX-HSA conjugate. These results indicated that MTX was coupled to HSA successfully and no polymerization of HSA took place.

After analysis of MTX-HSA conjugate by GPC analysis, HPLC analysis was used for identifying the MTX-HSA conjugate and quantitative analysis of free MTX.

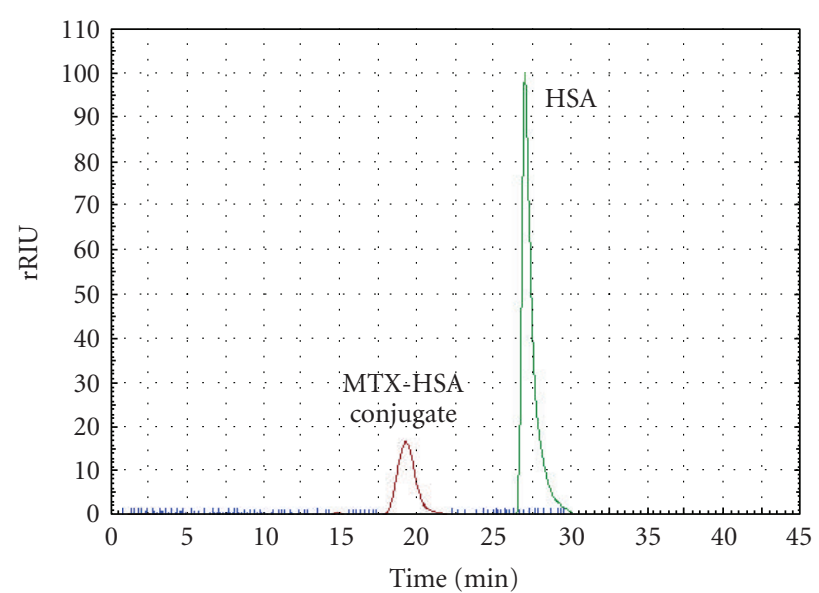

Figure 1: The GPC chromatogram of MTX-HSA conjugate and HSA.

\subsection{High-Performance Liquid Chromatography Analysis of} MTX and MTX-HSA Conjugate. MTX-HSA conjugates were characterized and tested for the content of free MTX using HPLC. The amount of free drug in the conjugates was determined by reverse-phase HPLC after precipitation of MTX-HSA conjugate and extraction of free MTX in an organic solvent. After addition of $2 \mathrm{~mL}$ of methanol containing $\mathrm{ZnSO}_{4}(1 \% \mathrm{w} / \mathrm{v})$ to the conjugates $(2 \mathrm{mg})$ dissolved in water $(0.5 \mathrm{~mL})$, the samples were mixed and centrifuged for 10 minutes at $5000 \mathrm{rpm}$. The supernatant was analyzed using a C18 column $(4.6 \times 250 \mathrm{~mm}$, pore size $5 \mu \mathrm{m}$; Teknokroma, Barcelona, Spain). The mobile phase (phosphate buffer $\mathrm{pH}$ 7.2: acetonitrile, $88: 12 \mathrm{v} / \mathrm{v}$ ) was delivered at a flow rate of $1.20 \mathrm{ml} / \mathrm{min}$ with a pump (WellChrom, K-1001, Knauer, Berlin, Germany). The free MTX was detected at $305 \mathrm{~nm}$ with an ultraviolet detector (WellChrom, K-2600, Knauer). Then a solution of methotrexate and a mixture solution of MTX and MTX-HSA conjugate were injected to the above system separately. In addition, $2 \mathrm{mg}$ of MTX-HSA conjugate and $0.5 \mathrm{mg}$ of MTX were dissolved in $0.5 \mathrm{ml} 0.01$ $\mathrm{N} \mathrm{NaOH}$ and mixed; after addition of $1 \mathrm{~mL}$ of ethyl acetate, the samples were mixed and centrifuged for 10 minutes at $15000 \mathrm{rpm}$. The aqueous phase was discarded, and the organic solvent evaporated under nitrogen flow. The residues redissolved in methanol $(100 \mu \mathrm{L})$ and were injected to the above HPLC system.

2.5. Preparation of MTX-HSA Nanoparticles. MTX (20 mg) with EDC $(15 \mathrm{mg})$ was dissolved in DMSO $(1.25 \mathrm{ml})$. The solution was placed in water bath at $50^{\circ} \mathrm{C}$ for $15 \mathrm{~min}$. Then the solution was cooled to room temperature and was added to HSA solution (250 mg HSA in $2 \mathrm{ml} \mathrm{PBS} \mathrm{pH} \mathrm{7.4)} \mathrm{at} \mathrm{the} \mathrm{rate}$ of $1 \mathrm{ml} / \mathrm{min}$ under constant stirring $(600 \mathrm{rpm})$. The MTXHSA conjugates so formed were cross-linked by adding $5 \mathrm{mg}$ EDC under constant stirring at room temperature for $4 \mathrm{~h}$ to produce MTX-HSA nanoparticles. Dialysis against PBS was performed (cellulose membrane, cutoff $12000 \mathrm{kDa}$ from Merck, Germany) for removing unbound MTX, EDC, and DMSO. Nanoparticles were then lyophilized at $-40^{\circ} \mathrm{C}$ for 48 h (Lyotrap Plus, LTE, scientific ltd, Oldham, UK). 
2.6. Determination of MTX/HSA Molar Ratio in Nanoparticles. $12.5 \mathrm{mg}$ of MTX-HSA nanoparticles was accurately weighed and dissolved in $4 \mathrm{ml}$ of $0.1 \mathrm{~N} \mathrm{NaOH}$. MTX content was determined by using UV absorbance of the solution in $372 \mathrm{~nm}$. The calibration plot of dissolved MTX in $0.1 \mathrm{~N}$ $\mathrm{NaOH}$ was linear in the range of $0.005-0.2 \mathrm{mg} / \mathrm{ml}$. It was assumed that the molar absorptivity of MTX did not change by conjugation [14]. HSA absorbance was negligible at this wavelength. HSA content of nanoparticles was determined using Total Protein Kit, Micro Lowry, Peterson's Modification from Sigma-Aldrich.

2.7. Measurement of Size and Size Distribution of Nanoparticles. Lyophilized nanoparticles were suspended in PBS to make a $1 \%$ solution. Then the size, polydispersity and zeta potential of MTX-HSA nanoparticles were determined by Zetasizer Nano ZS (Malvern Instruments, Worcestershire, UK).

2.8. Transmission Electron Microscopy (TEM). Lyophilized nanoparticles were characterized by Transmission Electron Microscope (Zeiss EM 900, Jena, Germany).

2.9. Differential Scanning Calorimetry (DSC). The thermal behavior of MTX, HSA, physical mixture of MTX and HSA, and MTX-HSA nanoparticles was studied by Differential Scanning Calorimetry (DSC-60, Shimadzu, Japan) over a range of 20 to $200^{\circ} \mathrm{C}$, at a scan rate of $10^{\circ} \mathrm{C}$ per min.

2.10. In Vitro Release of MTX. The release of MTX was evaluated by measuring the release of free MTX in phosphate buffer ( $\mathrm{pH}$ 7.4) and serum as follows.

An exact amount of MTX-HSA conjugate nanoparticles, MTX-HSA conjugate, and MTX (20 mg) was dissolved in $2 \mathrm{ml}$ of PBS (pH 7.4) separately. The solutions were introduced in dialysis tube (cellulose membrane, cutoff $12000 \mathrm{kDa}$, Merck, Germany). The tubes were placed into capped, wide mouth jars containing $10 \mathrm{ml}$ of PBS (pH 7.4) as release medium. These jars were placed in a shaker water bath $\left(37^{\circ} \mathrm{C}\right)$ for 72 hours. Every 24 hours, $0.1 \mathrm{ml}$ of release mediums was removed and replaced with $0.1 \mathrm{ml}$ of the same buffer solution. Samples were analyzed by high-performance liquid chromatography (HPLC) on a Teknokroma C18, 4.6× $250 \mathrm{~mm}$ column at $305 \mathrm{~nm}$ to determine the free MTX [15]. $30 \mathrm{mg}$ of MTX-HSA conjugate nanoparticles, MTX-HSA conjugate, and MTX were incubated with $3 \mathrm{ml}$ of foetal calf serum (FCS) and then were placed in $37^{\circ} \mathrm{C}$. Every $24 \mathrm{~h}$ free MTX was determined in FCS [15].

2.11. Determination of Amino Groups in Conjugates. The free amino groups of nanoparticles were determined using 2, 4, 6-trinitrobenzene-sulfunic acid (TNBS) [16]. After the reaction of nanoparticles with TNBS, nanoparticles were separated using Amicon Ultra-4 Centrifugal Filter Devices (Millipore, USA). The filtrate was analyzed for remaining free TNBS at $349 \mathrm{~nm}$.

2.12. In Vitro Cytotoxicity of Nanoparticles. Human breast cancer cells (T47D) were cultivated in RPMI-1640 medium

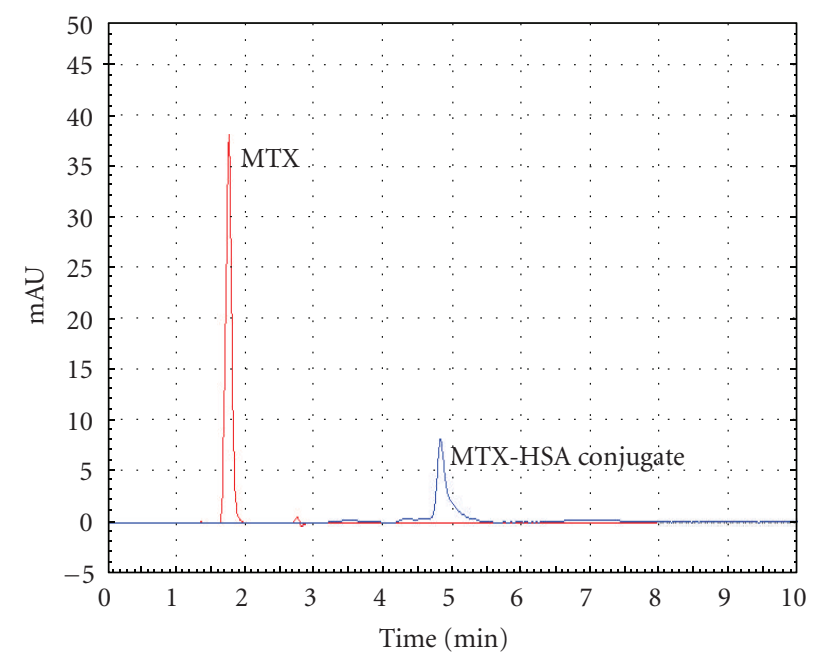

FIgURE 2: HPLC chromatogram of free MTX and MTX-HSA conjugate.

supplemented with $10 \%$ fetal bovine serum and $1 \%$ penicillin-streptomycin at $37^{\circ} \mathrm{C}$ in a humidified incubator with $5 \% \mathrm{CO}_{2}$. Cells were maintained in an exponential growth phase by periodic subcultivation.

T47D breast cancer cells were seeded in 96-well plates (Costar, IL, USA) at the density of 10000 viable cells/well and incubated $24 \mathrm{~h}$ to allow cell attachment. The medium was replenished every other day. The cells were incubated with the MTX and MTX-HSA nanoparticles at concentrations of 6.25 to $100 \mathrm{nM}$ for $96 \mathrm{~h}$. At appropriate time intervals, $20 \mu \mathrm{l}$ of MTT ( $5 \mathrm{mg} / \mathrm{ml}$ in PBS) was added to each well, and the culture medium containing MTT solution was removed after 3-4 hrs. The formazan crystals were dissolved in $100 \mu \mathrm{l}$ DMSO and read at $570 \mathrm{~nm}$. Cell viability was calculated by the following equation:

$$
\text { Cell viability }(\%)=\left(\frac{\text { Int }_{s}}{\text { Int }_{c}}\right) n \times 100,
$$

where $\mathrm{Int}_{s}$ is the colorimetric intensity of the cells incubated with the samples and $\mathrm{Int}_{c}$ is the colorimetric intensity of the cells incubated with the phosphate buffer ( $\mathrm{pH} 7.4)$ only as positive control. IC50, the drug concentration at which 50\% cell growth inhibited, was calculated by the curve fitting of the cell viability data using Prism 4.0 (Graphpad, San Diego, USA).

\section{Results and Discussion}

3.1. Characterization of MTX-HSA Conjugates. Figure 1 shows the GPC chromatogram of MTX-HSA conjugate and HSA. The GPC chromatogram of MTX-HSA conjugate showed a peak at $19.8 \mathrm{~min}$ whereas a single peak was found for HSA. There were not any additional peaks for free MTX and HSA in the GPC chromatogram of MTX-HSA conjugate. These results indicated that MTX was coupled to HSA successfully, and no polymerization of HSA took place.

Figure 2 shows the HPLC chromatogram of free MTX and MTX-HSA conjugate. Free MTX showed a single peak at 


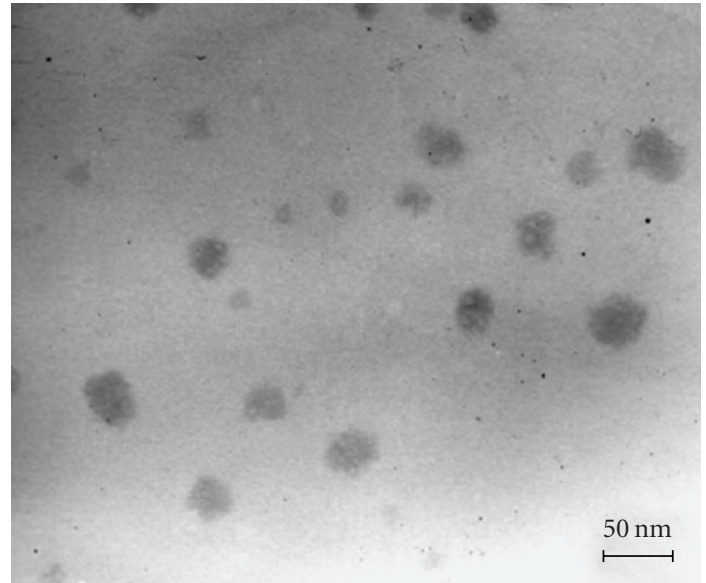

Figure 3: Transmission electron micrograph of MTX-HSA nanoparticles (MTX-HSA molar ratio: 2).

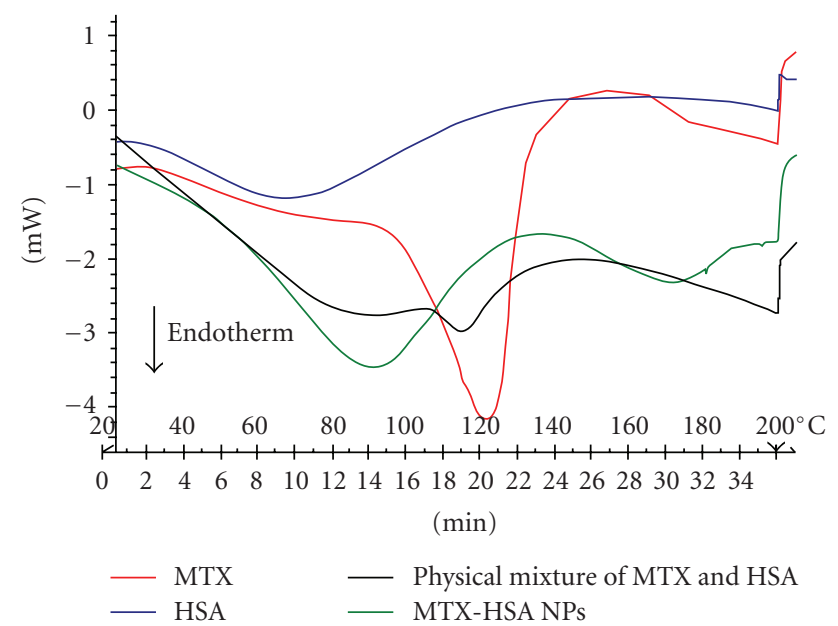

FIgURE 4: DSC thermogram of MTX, HSA, physical mixture of MTX and HAS and MTX-HSA nanoparticles.

1.9 min while the mixture solution of MTX-HSA conjugate and free MTX showed two separate peaks at 1.9 and $4.9 \mathrm{~min}$. After injection of residues of liquid-liquid extraction with ethyl acetate, only one peak was detected at $1.9 \mathrm{~min}$. Because in the process of liquid-liquid extraction with an organic solvent such as ethyl acetate, MTX-HSA conjugate remained in aqueous phase and only free MTX could have moved to the organic phase. This result confirms that the peak seen at $4.9 \mathrm{~min}$ is related to MTX-HSA conjugate.

\subsection{Characterization of MTX-HSA Conjugated Nanoparticles.} Three types of nanoparticles were prepared with MTXto-HSA molar ratios of approximately 2, 8, and 12 . The size, drug content, zeta potential, and polydispersity of various samples are reported in Table 1. Nanoparticles were analyzed with TEM. Figure 3 shows the transmission electron micrographs of nanoparticles. The diameter of nanoparticles determined by laser light scattering was in the range of 90 $150 \mathrm{~nm}$. As can be seen in Figure 3 the size of nanoparticles determined by TEM was approximately $50 \mathrm{~nm}$. Laser light scattering measurements were aimed at providing average values for the hydrodynamic diameter while TEM is a direct, model independent technique depicting the internal structure of the individual nanoparticles. Smaller sizes of nanoparticles determined by TEM compared with laser light scattering have been previously reported [2].

Figure 4 shows the DSC thermograms of MTX, HSA, physical mixture of MTX and HSA, and MTX-HSA conjugate nanoparticles. Differential scanning calorimetry (DSC) technique was used to confirm successful conjugation of methotrexate to human serum albumin $[17,18]$. The control experiments were carried out each using pure methotrexate, human serum albumin, and physical mixture of methotrexate and human serum albumin. The two endothermic peaks of physical mixture of methotrexate and human serum albumin $\left(78^{\circ} \mathrm{C}\right.$ and $\left.120^{\circ} \mathrm{C}\right)$ are similar to endothermic peaks of pure methotrexate $\left(122^{\circ} \mathrm{C}\right)$ and pure human serum albumin $\left(70^{\circ} \mathrm{C}\right)$ whereas an endothermic peak $\left(90^{\circ} \mathrm{C}\right)$ was observed for MTX-HSA conjugate. The analysis of calorimetric data suggested that conjugation of methotrexate to human serum albumin led to a shifting of the $T_{m}$ to lower temperatures. Compared to MTX, HSA and physical mixture of methotrexate and human serum albumin, apparent difference observed in the thermal behaviors and physicochemical properties of MTX-HSA conjugates supports the possibility of conjugation of methotrexate to human serum albumin.

Figure 5(a) shows the particle size of MTX-HSA nanoparticles cross-linked with different amount of EDC $(2.5,5,7.5,10,12.5$, and $15 \mathrm{mg})$. The results indicate that the amounts of EDC used for cross-linking did not have significant effect on the size of nanoparticles. Figure 5(b) shows that by increasing the amount of cross-linker the free amino groups per HSA molecule are decreased.

3.3. In Vitro Release of MTX. MTX-HSA nanoparticles were stable in both phosphate buffer ( $\mathrm{pH}$ 7.4) and fetal calf serum (FCS) at $37^{\circ} \mathrm{C}$. After 72 hours, only $5 \%$ and $9 \%$ of MTX were released from MTX-HSA nanoparticles in phosphate buffer and FCS media, respectively. Nanoparticles with different MTX/HSA molar ratios released similar amount of MTX at physiologic condition (PBS pH 7.4 and $37^{\circ} \mathrm{C}$ ) and after incubation with FCS. $6 \%$ and $10.2 \%$ of MTX were released from MTX-HSA conjugates in PBS pH 7.4 and FCS, respectively. It is obvious that $100 \%$ of free MTX were released in $\mathrm{PBS} \mathrm{pH} 7.4$ and $37^{\circ} \mathrm{C}$ and after incubation with FCS.

3.4. In Vitro Cytotoxicity of Nanoparticles. Figure 6 shows the in vitro cytotoxicity of free MTX drug and MTX-HSA nanoparticles with different molar ratios of MTX to HSA on T47D breast cancer cells. As can be seen the cytotoxicity of MTX-HSA nanoparticles on T47D cells was significantly higher than that of free MTX. It can also be seen that MTXHSA conjugates inhibited the cell proliferation even in lower concentration at $96 \mathrm{~h}$. The IC50 (the dose which produces 
TABLE 1: Preparation and characterization variables and parameters of MTX-HSA conjugate nanoparticles.

\begin{tabular}{lccccccc}
\hline Sample & MTX (mg) & HSA (mg) & $\begin{array}{c}\text { EDC used for } \\
\text { MTX } \\
\text { conjugation } \\
(\mathrm{mg})\end{array}$ & $\begin{array}{c}\text { MTX/HSA } \\
\text { molar ratio }\end{array}$ & $\begin{array}{c}\text { Particle } \\
\text { diameter } \\
(\mathrm{nm})\end{array}$ & $\begin{array}{c}\text { Zeta } \\
\text { Potential } \\
(\mathrm{mV})\end{array}$ & $\begin{array}{c}\text { Polydispersity } \\
\mathbf{1}\end{array}$ \\
$\mathbf{2}$ & 20 & 250 & 15 & $12 \pm 0.12$ & $150.3 \pm 5.1$ & $-16 \pm 0.2$ & $0.20 \pm 0.01$ \\
$\mathbf{3}$ & 20 & 350 & 15 & $8 \pm 0.18$ & $111.7 \pm 4.6$ & $-12 \pm 0.5$ & $0.10 \pm 0.01$ \\
\hline
\end{tabular}

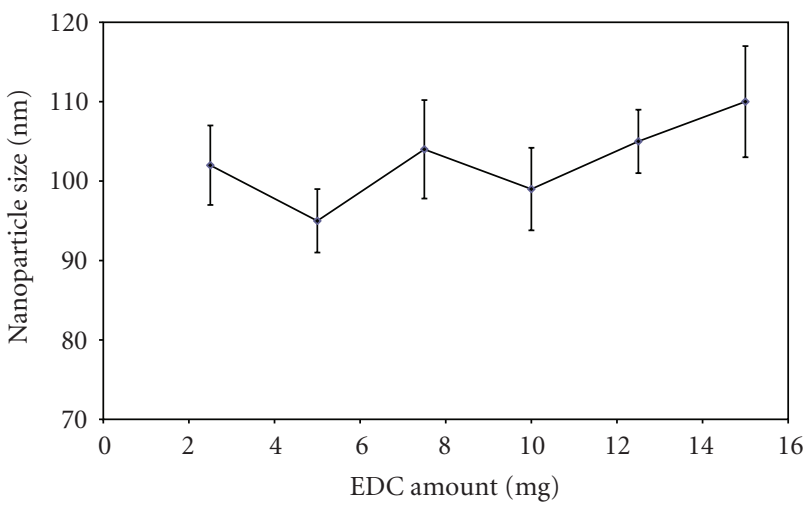

(a)

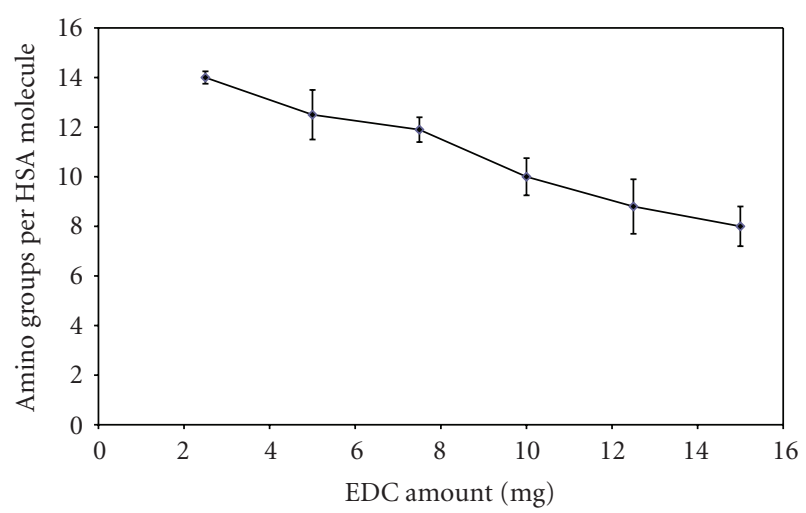

(b)

FIGURE 5: The effect of the amount of EDC on the size of MTXHSA nanoparticles (a) and the number of free amino groups on the surface of nanoparticles (b).

50\% inhibition of growth) of free MTX drug and MTXHSA nanoparticles on T47D cells with incubation time of $96 \mathrm{~h}$ is shown in Table 2. These data show that MTX-HSA nanoparticles decreased the IC50 value of MTX on T47D breast cancer cells in comparison with free MTX.

Drug-carrier conjugated systems may be internalized by different cell types, suggesting that they may be a suitable carrier system for the transport of drugs into cells [19]. Nanoparticles formulations might improve drug deposition and activity while reducing systemic toxicity and adverse events [20]. The conjugation of cytotoxic drugs to carriers can decrease the adverse reaction of these drugs. There are different strategies for using albumin as a drug delivery

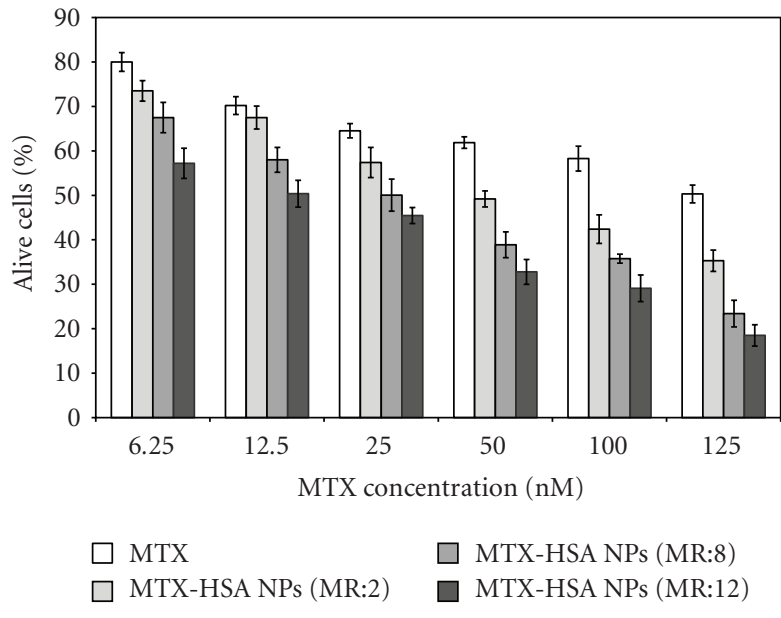

FIGURE 6: Cytotoxicity effect of free methotrexate and MTX-HSA NPs on T47D breast cancer cells after $96 \mathrm{~h}$.

system for cancer therapy [21]. One strategy may be the preparation of albumin particles loaded with cytotoxic agent [8]. The disadvantage of this method is that release of the cytotoxic agent in blood circulation induces side effects. Another strategy is the conjugation of cytotoxic agents to HSA $[3,22]$. The disadvantage of this system is the lower toxicity of the conjugated system in comparison to the free drug [22]. However, there are other reports showing higher cytotoxicity for the conjugated systems including the current study [3]. In this study we tried to prepare nanoparticles from MTX-HSA conjugates to increase the cytotoxicity of the system on one hand and to reduce the presumed side effects of the system on another hand. Three types of nanoparticles with different molar ratios of MTX to HSA were produced by variation of the amount of HSA used in synthesis. Carboxylic acid groups of MTX were activated by EDC coupling agent. These activated groups react with primary amino groups of albumin. We used DMSO as a solvent for both MTX and EDC. DMSO plays the role of desolvating agent for HSA molecules. Nanoparticles were prepared by desolvation process and then were stabilized by addition of different amounts of EDC as cross-linker. EDC acts as the crosslinking agent between carboxylic acid groups of HSA and free amino groups of HSA. Figure 5(a) demonstrates that the concentration of cross-linker above 2\% (5 mg EDC for $250 \mathrm{mg}$ albumin) has no significant effect on the size of nanoparticles. Increasing 
TABLE 2: IC50 of MTX and MTX-HSA nanoparticles on T47D breast cancer cells after $96 \mathrm{~h}$.

\begin{tabular}{|c|c|c|c|c|}
\hline & MTX & $\begin{array}{c}\text { MTX-HSA NPs } \\
(\mathrm{MR}: 2)^{*}\end{array}$ & $\begin{array}{c}\text { MTX-HSA NPs } \\
\text { (MR:8) }\end{array}$ & $\begin{array}{c}\text { MTX-HSA NPs } \\
(\mathrm{MR}: 12)\end{array}$ \\
\hline IC50 (nM) & $123.4 \pm 4.2$ & $45.6 \pm 2.5$ & $24.6 \pm 3.4$ & $14.3 \pm 2.9$ \\
\hline
\end{tabular}

${ }^{*}$ MR: molar ratio of MTX/HAS.

the amount of cross-linker decreased the free amino groups of nanoparticles (Figure 5(b)). Low drug release from the system both in phosphate buffer ( $\mathrm{pH} 7.4)$ and in serum indicates the stability of the nanoparticles. Consequently, after I.V. administration of nanoparticles, the concentration of free MTX in plasma will be very low, hence less side effects are expected. The results of cytotoxicity test indicated the higher cytotoxicity of MTX-HSA nanoparticles compared to that of free MTX free drug. The cell viability measured at $125 \mathrm{nM}$ drug concentration was decreased from $50.3 \%$ for MTX free drug to $35.3 \%, 23.4 \%$, and $18.5 \%$ for the MTXHSA nanoparticles with MTX-to-HSA molar ratio of 2, 8, and 12, respectively, after $96 \mathrm{~h}$ of incubation. As can be seen in Figure 6, MTX-HSA nanoparticles prepared using higher molar ratio of MTX to HSA showed better inhibition of cell proliferation even at low drug concentration $(6.25 \mathrm{nM})$ $(P<.05)$. The IC50 of MTX in the MTX-HSA nanoparticles with molar ratio of 2, 8, and 12 is 2.5-, 5-, and 10-fold lower than that of free MTX on T47D cells, respectively.

The increased antitumor activity of MTX-HSA nanoparticles may be related to enhanced transendothelial cell transport of albumin which is mediated by the gp60 (albondin) receptor and caveolar transport $[23,24]$. Albumin binding to gp60 activates caveolin-1 resulting in the formation of caveoli, which transport albumin and other plasma constituents across the endothelial cell to the interstitial space. The increased antitumor activity of MTX-HSA nanoparticles may also be related to the enhanced intratumor delivery of MTX. The gp60 receptors are specific for albumin and, once activated, allow for transport of albumin complexes across blood vessel wall barriers into underlying tumor tissue [25]. Moreover, MTX has similar structure to folate. It is possible that the molecules of methotrexate on the surface of nanoparticles play the role of targeting moieties and increase the transendothelial transport and cytotoxic effect of MTXHSA nanoparticles.

\section{Conclusion}

MTX was successfully conjugated to HSA using EDC. The conjugates were then crosslinked using EDC to prepare nanoparticles with a size range of 90 to $150 \mathrm{~nm}$. The nanoparticles prepared in this study were shown to be more soluble in aqueous and PBS media. It was also shown that the MTX-HSA conjugated nanoparticles were of more cytotoxic effect on T47D cell line than MTX free drug. In conclusion it can be said that the MTX-HSA nanoparticles were showed to be superior in vitro antitumor activity when compared to MTX free drug. These nanoparticles appear to be a good candidate for further antitumor tests in animal models.

\section{Abbreviations}

HSA: Human serum albumin

MTX: $\quad$ Methotrexate

MTX-HSA: Methotrexate-Human serum albumin

EDC: $\quad$ 1-ethyl-3-(3-dimethylaminopropyl) carbodiimide $\mathrm{HCl}$

\section{References}

[1] W. Chen, B. Gu, H. Wang, J. Pan, W. Lu, and H. Hou, "Development and evaluation of novel itraconazole-loaded intravenous nanoparticles," International Journal of Pharmaceutics, vol. 362, no. 1-2, pp. 133-140, 2008.

[2] S. Das, R. Banerjee, and J. Bellare, "Aspirin loaded albumin nanoparticles by coacervation: implications in drug delivery," Trends in Biomaterials and Artificial Organs, vol. 18, no. 2, pp. 203-212, 2005.

[3] F. Esmaeili, R. Dinarvand, M. H. Ghahremani et al., "Docetaxel-albumin conjugates: preparation, in vitro evaluation and biodistribution studies," Journal of Pharmaceutical Sciences, vol. 98, no. 8, pp. 2718-2730, 2009.

[4] T. Tanaka, P. Decuzzi, M. Cristofanilli et al., "Nanotechnology for breast cancer therapy," Biomedical Microdevices, vol. 11, no. 1, pp. 49-63, 2009.

[5] R. Hertz, J. Lewis Jr., and M. B. Lipsett, "Five years' experience with the chemotherapy of metastatic choriocarcinoma and related trophoblastic tumors in women," American Journal of Obstetrics and Gynecology, vol. 82, no. 3, pp. 631-640, 1961.

[6] J. R. Bertino, "Ode to methotrexate," Journal of Clinical Oncology, vol. 11, no. 1, pp. 5-14, 1993.

[7] S. Friberg and S. Mattson, "On the growth rates of human malignant tumors: implications for medical decision making," Journal of Surgical Oncology, vol. 65, no. 4, pp. 284-297, 1997.

[8] K. Santhi, S. A. Dhanaraj, M. Koshy, S. Ponnusankar, and B. Suresh, "Study of biodistribution of methotrexate-loaded bovine serum albumin nanospheres in mice," Drug Development and Industrial Pharmacy, vol. 26, no. 12, pp. 1293-1296, 2000.

[9] S. Jayaprakash, S. Mohamed Halith, P. U. Mohamed Firthouse, K. Kulaturanpillai, Abhijith, and M. Nagarajan, "Preparation and evaluation of biodegradable microspheres of methotrexate," Asian Journal of Pharmaceutics, vol. 3, no. 1, pp. 26-29, 2009.

[10] L. W. Seymour, "Passive tumor targeting of soluble macromolecules and drug conjugates," Critical Reviews in Therapeutic Drug Carrier Systems, vol. 9, no. 2, pp. 135-187, 1992.

[11] G. Stehle, H. Sinn, A. Wunder et al., "Plasma protein (albu$\mathrm{min}$ ) catabolism by the tumor itself-implications for tumor metabolism and the genesis of cachexia," Critical Reviews in Oncology/Hematology, vol. 26, no. 2, pp. 77-100, 1997.

[12] N. Endo, Y. Kato, and Y. Takeda, "In vitro cytotoxicity of a human serum albumin-mediated conjugate of methotrexate with anti-MM46 monoclonal antibody," Cancer Research, vol. 47, no. 4, pp. 1076-1080, 1987. 
[13] F. Esmaeili, R. Dinarvand, M. H. Ghahremani, S. N. Ostad, H. Esmaily, and F. Atyabi, "Cellular cytotoxicity and invivo biodistribution of docetaxel poly(lactide-co-glycolide) nanoparticles," Anti-Cancer Drugs, vol. 21, no. 1, pp. 43-52, 2010.

[14] A. Kosasih, B. J. Bowman, R. J. Wigent, and C. M. Ofner III, "Characterization and in vitro release of methotrexate from gelatin/methotrexate conjugates formed using different preparation variables," International Journal of Pharmaceutics, vol. 204, no. 1-2, pp. 81-89, 2000.

[15] B. Nuernberg, M. Kohlbrenner, R. Faulkner, and D. Furst, "Rapid quantitation of methotrexate and its metabolites in human serum, urine and bile, using solid-phase extraction and high-performance liquid chromatography," Journal of Chromatography, vol. 487, no. 2, pp. 476-482, 1989.

[16] A. F. S. A. Habeeb, "Determination of free amino groups in proteins by trinitrobenzenesulfonic acid," Analytical Biochemistry, vol. 14, no. 3, pp. 328-336, 1966.

[17] N. M. Anande, S. K. Jain, and N. K. Jain, "Con-A conjugated mucoadhesive microspheres for the colonic delivery of diloxanide furoate," International Journal of Pharmaceutics, vol. 359, no. 1-2, pp. 182-189, 2008.

[18] G. Yousefi, S. M. Foroutan, A. Zarghi, and A. Shafaati, "Synthesis and characterization of methotrexate polyethylene glycol esters as a drug delivery system," Chemical and Pharmaceutical Bulletin, vol. 58, no. 2, pp. 147-153, 2010.

[19] B. Wang, W. Qiao, Y. Wang, L. Yang, Y. Zhang, and P. Shao, "Cancer therapy based on nanomaterials and nanocarrier systems," Journal of Nanomaterials, vol. 2010, Article ID 796303, 9 pages, 2010.

[20] M. Brzoska, K. Langer, C. Coester, S. Loitsch, T. O. F. Wagner, and C. V. Mallinckrodt, "Incorporation of biodegradable nanoparticles into human airway epithelium cells - in vitro study of the suitability as a vehicle for drug or gene delivery in pulmonary diseases," Biochemical and Biophysical Research Communications, vol. 318, no. 2, pp. 562-570, 2004.

[21] F. Kratz, "Albumin as a drug carrier: design of prodrugs, drug conjugates and nanoparticles," Journal of Controlled Release, vol. 132, no. 3, pp. 171-183, 2008.

[22] M. C. Garnett and R. W. Baldwin, "An improved synthesis of a methotrexate-albumin-791T/36 monoclonal antibody conjugate cytotoxic to human osteogenic sarcoma cell lines," Cancer Research, vol. 46, no. 5, pp. 2407-2412, 1986.

[23] T. A. John, S. M. Vogel, C. Tiruppathi, A. B. Malik, and R. D. Minshall, "Quantitative analysis of albumin uptake and transport in the rat microvessel endothelial monolayer," American Journal of Physiology, vol. 284, no. 1, pp. L187-L196, 2003.

[24] W. Schubert, P. G. Frank, B. Razani, D. S. Park, C.-W. Chow, and M. P. Lisanti, "Caveolae-deficient endothelial cells show defects in the uptake and transport of albumin in vivo," Journal of Biological Chemistry, vol. 276, no. 52, pp. 4861948622, 2001.

[25] N. Desai, V. Trieu, Z. Yao et al., "Increased antitumor activity, intratumor paclitaxel concentrations, and endothelial cell transport of cremophor-free, albumin-bound paclitaxel, ABI007, compared with cremophor-based paclitaxel," Clinical Cancer Research, vol. 12, no. 4, pp. 1317-1324, 2006. 

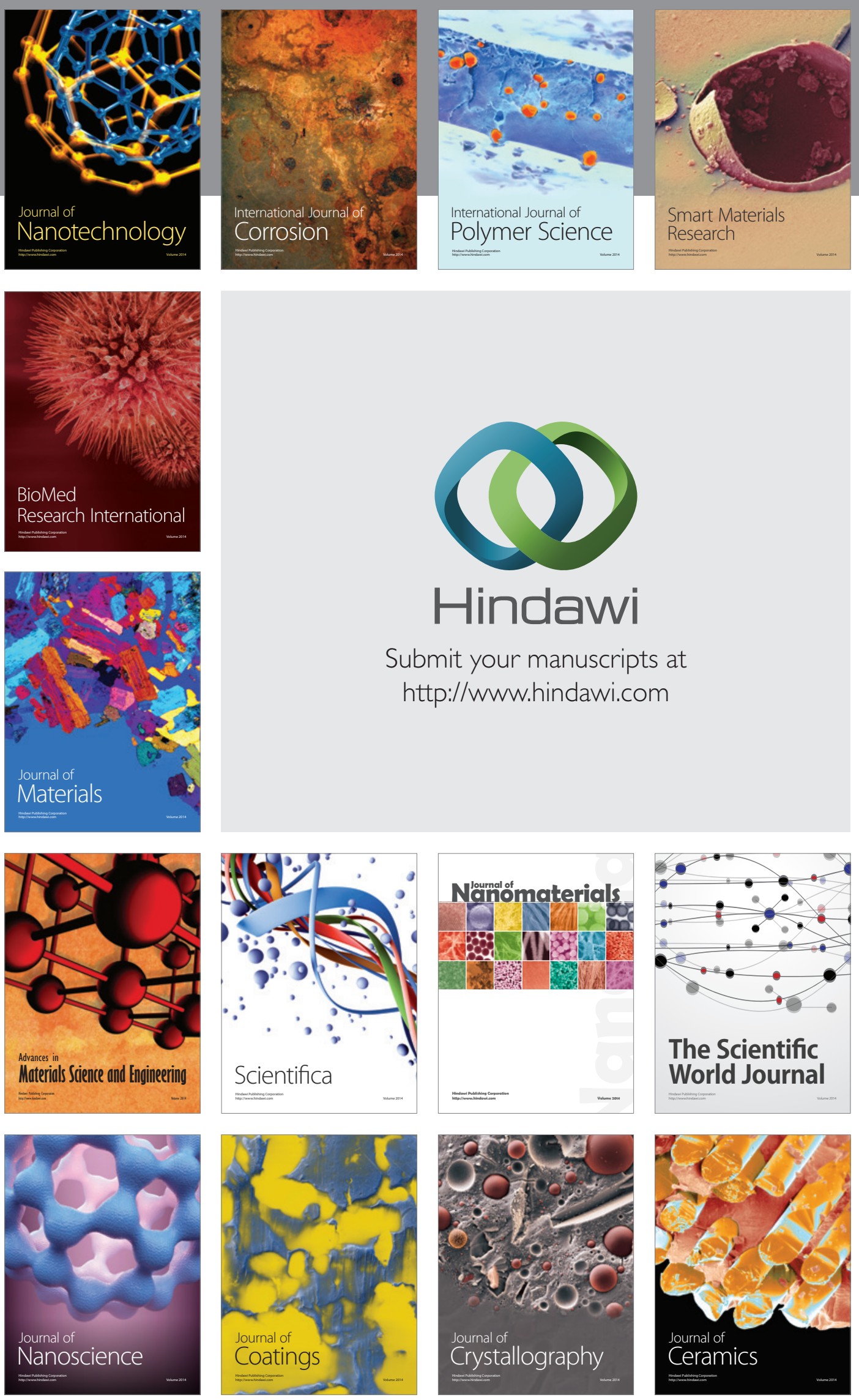

The Scientific World Journal

Submit your manuscripts at

http://www.hindawi.com

\section{World Journal}

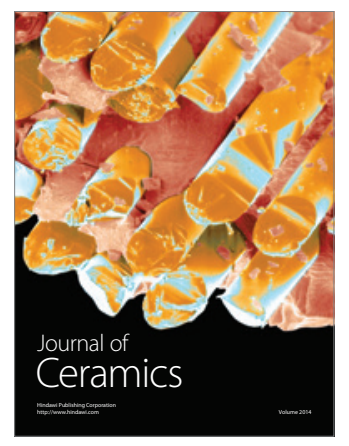

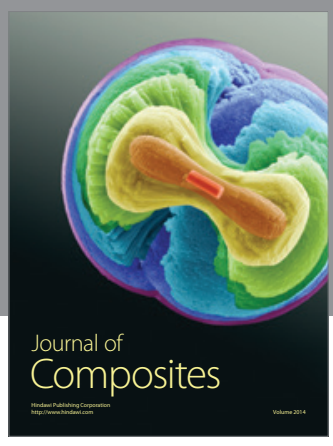
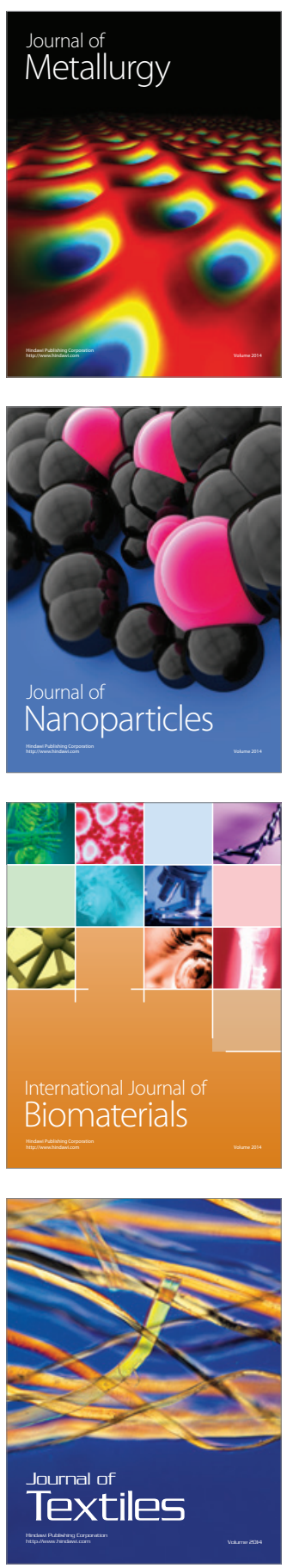